This is the peer reviewed version of the following article:

Bigoni M, Bortolotti S, Casari M, Gambetta D (2019), At the Root of the North-South Cooperation Gap in Italy: Preferences or Beliefs?. Econ J. DOI:10.1111/ecoj.12608 which has been published in final form at https://doi.org/10.1111/ecoj.12608.

This article may be used for non-commercial purposes in accordance with Wiley Terms and Conditions for Use of Self-Archived Versions. 


\title{
At the root of the North-South cooperation gap in Italy Preferences or beliefs?*
}

\author{
Maria Bigoni, Stefania Bortolotti, Marco Casari and Diego Gambetta
}

\begin{abstract}
The sharp gap in development between the North and the South of Italy represents a paradigmatic case of persistent within-country disparities. The evidence suggests that this gap could depend on a difference in the ability to cooperate. We investigate experimentally three possible sources of this difference, and find that Northerners and Southerners share the same pro-social preferences, but differ both in their belief about cooperativeness and in the aversion to social risk - respectively more pessimistic and stronger among Southerners. Intervention or events that reduced pessimistic beliefs should directly boost cooperation.
\end{abstract}

Keywords. Betrayal aversion, conditional cooperation, experiments, Italy.

JEL codes: C72, C93, Z13

Stark regional disparities in income are commonly found in many countries, (Ezcurra and Rodríguez-Pose, 2013) and policies aimed at reducing within-country differences have commanded much effort and attention in Europe and elsewhere. Cohesion polices typically focus on equalizing opportunities and welfare conditions across areas, neglecting the possibility that people in different regions may, for a variety of causes, react differently to similar institutions and opportunities (Brosig-Koch et al., 2011; Bigoni et al., 2016, Rustagi and Veronesi, 2016).

Here we explore two such causes, namely differences in preferences and expectations across regions. We focus on the Italian North-South divide, a widely-debated case of seemingly intractable within-country differences Banfield and Fasano, 1958, Putnam et al., 1993, Guiso et al. 2004; Cartocci, 2007; Buonanno et al., 2009; Nannicini et al., 2013). Previous studies

\footnotetext{
${ }^{*}$ Corresponding author: Marco Casari, Department of Economics, University of Bologna, Piazza Scaravilli 2, 40126 Bologna, Italy. Email: marco.casari@unibo.it, Phone: +39 051209 8662, Fax: +39051 2098493. The authors thank participants at the NIBS workshop in Nottingham, ESA European meeting in Heidelberg, C-SEB workshop in Cologne, Social Capital and Regional Divides Workshop in Cagliari, ESA European meeting in Bergen, $11^{\text {th }}$ Nordic Conference on Behavioral and Experimental Economics in Oslo, $2^{\text {nd }}$ Workshop on Cultural Transmission and Social Norms and seminar participants at the Universities of Bologna, Trento, LUISS Guido Carli, and Federico II for helpful comments and suggestions. M. Casari gratefully acknowledges support from an ERC Starting Grant (No. 241196). The usual disclaimer applies.
} 
record a resilient behavioural difference in cooperation that holds even if variations in geography, informal institutions, and incentives are experimentally suppressed, and after controlling for socio-demographic characteristics: the ability to cooperate is lower in the South than in the North of Italy (Bigoni et al., 2016) 11 Through a set of experiments, in this paper we explore the behavioural roots of the North-South gap in cooperation. We consider three main conjectures, related to: (i) preferences for conditional cooperation; (ii) beliefs about the cooperation of others; and (iii) aversion to social risk.

Our first conjecture is that the North-South gap could be determined by a difference in the prevalence of conditional cooperators across Italy. Conditional cooperators are willing to cooperate provided that other people cooperate as well, so they act pro-socially not out of sheer altruism, but of a reciprocal response to others' actions (Fischbacher et al. , 2001). Conditional cooperators are widespread in society, but their share varies greatly across and within countries (Kocher et al. 2008; Rustagi and Veronesi, 2016). The prevalence of conditional cooperators also correlates with the ability to establish and sustain large-scale cooperation (Rustagi et al. 2010). The actual behaviour of conditional cooperators depends on their beliefs on others' cooperation as well as on their propensity to bear the risk of being exploited, to which we turn next.

Our second conjecture is that Southerners' expectations on others' cooperation could be more pessimistic than those of Northerners. Taking expectations into consideration is crucial: consider for instance the extreme case of a population of perfect conditional cooperators. Here, beliefs become self-confirming prophecies. If everyone expects that most of the others will cooperate, they will indeed cooperate. If instead people expect others to free-ride, they will do the same. Either way, expectations would be correct in equilibrium. The role of beliefs has been shown to be important in the repeated interactions not only of perfect conditional cooperators, but in that of heterogeneous players (Fischbacher and Gächter, 2010). If expectations are different, the North-South gap could persist despite a similar frequency of conditional cooperators, i.e. a similar presence of pro-social preferences.

Our third conjecture is that the North-South gap in cooperation could be driven by a dif-

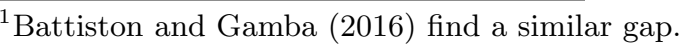


ference in betrayal aversion, that is, the aversion to the risk of being cheated. There is evidence that people are more averse to social risk than to risk of nature, that is towards risk of equally harmful events determined by mere chance rather than by others' choices (Bohnet and Zeckhauser, 2004). Betrayal aversion seems to vary in intensity across societies (Bohnet et al., 2008). In social dilemmas, betrayal aversion plays a relevant role because the fear to be exploited by free riders could deter contributors (Cubitt et al., 2017) 2 Consider, for instance, two conditional cooperators with the same optimistic expectations but different attitudes toward social risk. The one with a higher tolerance of social risk might cooperate in full, while the other, perceiving the cost associated to being exploited as too high might decide not to contribute at all.

These three mechanisms carry distinct policy implications. If Northerners and Southerners share the same preference for conditional cooperation, but have different expectations about others' cooperation level, a shift in beliefs, generated for instance by migration or by a positive political or institutional shock, could positively impact cooperation levels. If instead what matters is a difference in the strength and support of conditional cooperation, a change is harder to achieve (as well as controversial) as it would involve reshaping individual preferences; it would also imply a very long-term effort given the high degree of persistence due to the intergenerational transmission of preferences (Bisin and Verdier, 2000; Dohmen et al., 2012). In so far betrayal aversion is a preference, the same conclusions would follow also if differences in betrayal aversion were found to matter.

In order to disentangle the three factors that could contribute to the ability to achieve and sustain cooperation, we designed two experiments. In Experiment 1, we study preferences for conditional cooperation in a public good game holding expectations constant. In Experiment 2, we study individual expectations on others' cooperative behaviour, and betrayal aversion in a trust game. The design and the results of the two experiments are presented in Section 2 and 3, respectively. Section 4 discusses our findings and concludes.

\footnotetext{
${ }^{2}$ Results in Cubitt et al. (2017) indicate that betrayal aversion is correlated with conditional cooperation only through beliefs, being stronger among pessimistic conditional cooperators.
} 


\section{Experiment 1 on Conditional Cooperation}

\subsection{Design}

To measure conditional cooperation, we followed the design proposed by Fischbacher et al. (2001) $!^{3}$ Subjects were randomly assigned to groups of $N=4$, and received an endowment of $w=20$ tokens, which they could allocate between a group project $\left(g_{i}\right)$ - with a marginal per capita return $(\alpha)$ of 0.4 - and a private account $\left(w-g_{i}\right)$. Earnings were determined as follows:

$$
\pi_{i}=w-g_{i}+\alpha \sum_{j=1}^{N} g_{j}
$$

Each subject had to make two types of decisions. The first decision is the unconditional choice of how many tokens to contribute to the group project. The second type of decisions are a series of conditional contribution choices. Subjects had to indicate how many tokens they were willing to contribute, given the average contribution to the group project of the other group members. The scenarios for others' contributions ranged from 0 to 20 tokens, in steps of 1 (i.e., strategy method). Each subject was paid only for one of his decisions. The relevant decision for payment was the unconditional one for three members of each group. For the fourth group member, selected at random, the relevant decision was the conditional choice corresponding to the realised average contribution of the others. At the end of the session, subjects were informed about their relevant decision, the total contributions to the group project, and their earnings. Conditional contribution choices provide a generalised measure of social preferences in a Public Good Game. Since we are eliciting answers for each possible contingency of others' contribution levels, the composition of the subject pool should not affect the choice profile.

\subsection{Recruitment Strategy and Experimental Procedures}

We recruited participant from the University of Bologna subject pool, which attracts students from all Italian regions. ${ }^{4}$ The recruitment was aimed at covering the South and the North of Italy, excluding the Centre; to this end, we invited only subjects born in a specific set of regions.

\footnotetext{
${ }^{3}$ After the conditional cooperation task, we also elicited time preferences, which will be analysed in a separate paper (see instructions in the Online Appendix).

${ }^{4}$ Our study is not the first to rely on the subject pool of a single institution to draw inferences about behaviour across cultures. Notable examples are Barr and Serra (2010) who relied on college students in Oxford and Bornhorst et al. (2010) that investigated trust among European PhD students who moved to Italy for their studies.
} 
Figure 1: North and South of Italy

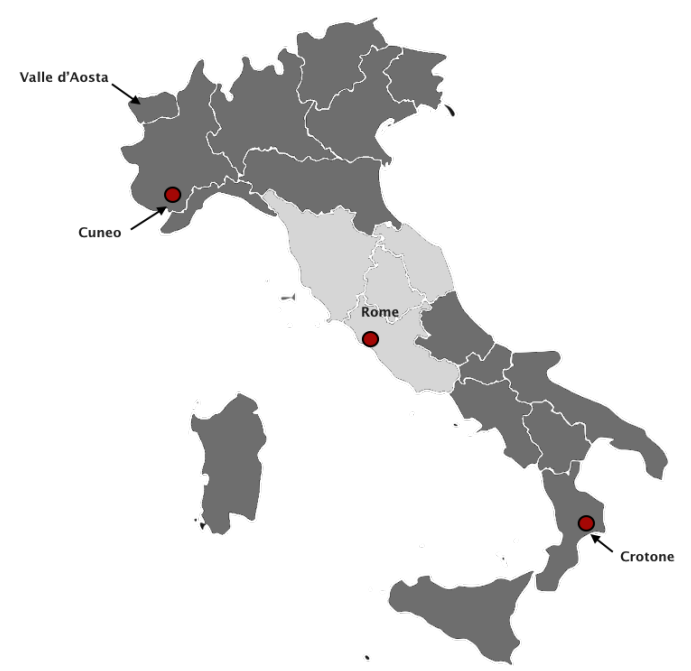

Notes: Classification in North, Center, and South macro-regions follows the definitions of the National Institute of Statistics (ISTAT). We had participants from all shaded regions, except Valle d'Aosta (North), the smallest Italian region. 231 participants were born in the South and 193 in the North. In the analysis we excluded data for the 24 participants born in the Central regions and 2 born abroad, and concentrate on the North-South gap.

The recruitment strategy and the procedures were the same for both Experiment 1 and Experiment 2. The vast majority of participants in both experiments completed primary school in their macro-area of origin ( $98 \%$ for the South, $91 \%$ for the North), and had at least one parent born there $(100 \%$ and $85 \%$ respectively), which suggests that they have absorbed the social norms of the area where they come from.

We were able to recruit students scattered in all regions of North and South, which gives a nation-wide dimension to the findings (Figure 1). Such an extensive coverage of the national territory would be difficult with other approaches. Students represent a very homogeneous population in terms of age and education level hence enhancing the control of the experiment. College-educated participants are well suited to handle some complexities embedded in the experimental designs, which instead would be an obstacle when using a representative sample of the population. Here we focus on students who moved to Bologna to study, which may raise issues of self-selection. Suppose, for instance, that students from the South who moved to Bologna are more cooperative than those who stayed in the South. If that was true, our experiment would overestimate the cooperation level of the Southerners. We cannot rule this out completely. Still, a recent experiment on the college choices of high-school students from 
the South (Calabria) shows that, at the aggregate level, preferences for conditional cooperation do not differ between those who moved to an University in the Centre-North of Italy and those who stayed in the South (Casari et al., 2018) . $^{5}$

Procedures. Each subject participated in only one of the sessions of either Experiment 1 or Experiment 2. Upon arrival, subjects were seated at a visually separated desk and no form of communication was allowed during the session. The instructions were read aloud to ensure common knowledge and then subjects answered the control questions before engaging in the task. At the end of the sessions, we administered a computerised questionnaire where we elicited socio-demographic characteristics. Earnings were expressed in tokens and payments were made in private. Recruitment was done using ORSEE (Greiner, 2015) and the experiment was implemented through z-Tree software applications (Fischbacher, 2007). The sessions were conducted at the Bologna Laboratory for Experiments in Social Sciences (BLESS) and at the Laboratorio di Economia Sperimentale (LES) in Forlì.

Experiment 1 included 7 sessions with a number of participants ranging from 19 to 24, for a total of 134 subjects ${ }^{6}$ A session lasted on average about 1 hour. The conversion rate was 4 tokens per Euro and the overall average per-capita earnings were 18 Euros including a 4 Euros show-up fee 7

\subsection{Results for Experiment 1}

Result 1 Participants from the South and from the North display a similar preference for conditional cooperation.

Figure 2 and Table 1 provide support for Result 1 1 . On average, participants' contribution increased with the contributions of others. Such link is present both for participants from the North and from the South. These phenomenon is illustrated by the positive slope of the lines in

\footnotetext{
${ }^{5}$ In a 2-player public good game played with the strategy method (Fischbacher et al., 2001$)$.

${ }^{6}$ We explicitly mention the geographical constraint in the recruitment message for the first sessions, while in the last four sessions we were able to send the invitation exclusively to subjects born in the regions of interest, thanks to an update of the recruitment software.

${ }^{7}$ Average per capita earnings in Experiment 1 include the time-preference task, not discussed here, which were paid via bank transfer.
} 


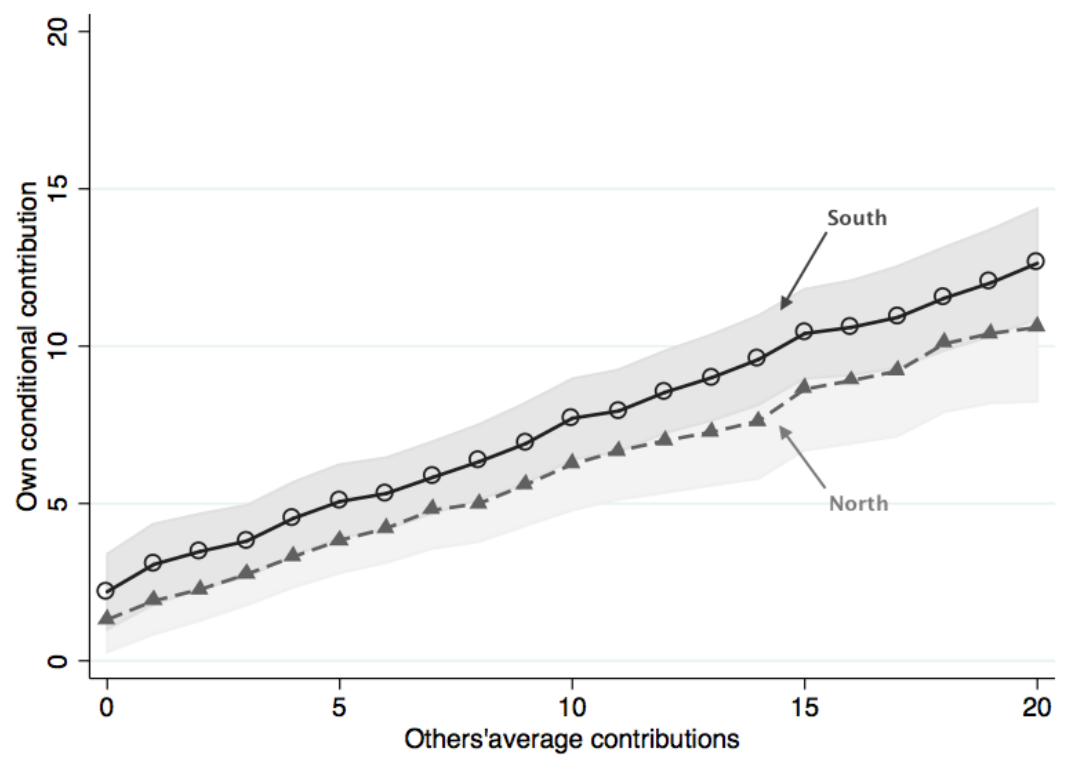

Figure 2 and by the positive correlation at the individual level between own and others' contributions (North: avg. corr. $=0.69, N=52$; South: avg. corr. $=0.71, N=82$ ). Participants from the North, though, do not differ in a statistically significant manner from those from the South with respect to this correlation (p-value $=0.936$, two-sided Wilcoxon rank-sum test, $N_{N}=41$ and $\left.N_{S}=73\right) .8$

A regression analysis confirms these findings. Table 1 presents results from OLS regressions explaining the level of contributions conditional on others' choices when pooling participants from the North and the South. In Model 1, we include the variable Others' average contribution and a set of controls. Others' average contributions is positive and highly significant, hence showing the presence of conditional cooperation. In Model 2, we include a dummy for those born in the North and interact the variable Others' average contributions with the North and South dummies. The difference between the two estimated coefficients of the interacted variables is only marginally statistically significant ( $\mathrm{p}$-value $=0.058$ ). In Model 3 we replicate the regression of Model 2 on a rooted sample, which is restricted to subjects who have completed the primary school in the macro-region of birth, and have at least one parent born in the same macro-region. In this case no significant difference emerges between the behaviour of subjects

\footnotetext{
${ }^{8}$ The correlation is based on a Spearman test and this measure is not defined for all observations.
} 
Table 1: Regression on Conditional Cooperation

\begin{tabular}{|c|c|c|c|}
\hline \multirow{2}{*}{$\begin{array}{l}\text { Dep. var.: Contribution to } P G G \\
\text { for a given contribution of others }\end{array}$} & \multicolumn{2}{|c|}{ Entire sample } & \multirow{2}{*}{$\begin{array}{l}\text { Rooted sample } \\
\text { Model } 3\end{array}$} \\
\hline & Model 1 & Model 2 & \\
\hline Others' average contribution & $\begin{array}{l}0.495^{* * *} \\
(0.011)\end{array}$ & & \\
\hline $\begin{array}{l}\text { Others' average contribution } \mathrm{x} \\
\text { North }\end{array}$ & & $0.469^{* * *}$ & $0.469^{* * *}$ \\
\hline $\begin{array}{l}\text { Others' average contribution } \mathrm{x} \\
\text { South }\end{array}$ & & $\begin{array}{l}(0.018) \\
0.512^{* * *}\end{array}$ & $\begin{array}{l}(0.021) \\
0.506^{* * *}\end{array}$ \\
\hline North & & $\begin{array}{r}(0.014) \\
-0.569 \\
(1.088)\end{array}$ & $\begin{array}{r}(0.014) \\
-1.365 \\
(1.252)\end{array}$ \\
\hline Controls & Yes & Yes & Yes \\
\hline Constant & $\begin{array}{c}5.603^{* * *} \\
(1.093)\end{array}$ & $\begin{array}{l}5.509^{* * *} \\
(1.100)\end{array}$ & $\begin{array}{l}5.758^{* * *} \\
(1.126)\end{array}$ \\
\hline $\begin{array}{l}\text { N.obs., N.subjects } \\
\mathrm{R}^{2}\end{array}$ & $\begin{array}{r}2814,134 \\
0.255 \\
\end{array}$ & $\begin{array}{r}2814,134 \\
0.259\end{array}$ & $\begin{array}{r}2541,121 \\
0.265\end{array}$ \\
\hline
\end{tabular}

Notes: OLS regression with individual level random-effects. Controls: Male takes value 1 for males and 0 for females. Experiment run in Forli takes value 1 for the sessions run in the Forlí campus and 0 for the sessions run in the Bologna campus of the University of Bologna. Low task comprehension: to account for participants' understanding of instructions, we use the answering time and the number of mistakes they did in the control questions. We classified the task comprehension as low for those subjects who were in the last decile according either to their total answering time, or to their total number of mistakes (this measure was built at the session level). The Impulsivity score ranges from 0 to 3 and is the total score in a non-incentivised Cognitive Reflection Test (Frederick 2005), while the Logic score ranges from 0 to 2 and is based on a simplified version of the Raven's progressive matrices test (not incentivised). *** statistical significance at the $1 \%$ level.

from North and South $(\mathrm{p}$-value $=0.247)$. Result 1 holds after controlling for gender, task comprehension, cognitive skills and a variety of other confounding factors.

This aggregate behaviour is compatible with a variety of individual patterns of conditional cooperation. For this reason, we classify subjects into four types. Following Fischbacher et al. (2001), we label a subject as a conditional cooperator if he has a highly significant (p-value $\leq$ $1 \%$ ) and positive Spearman rank correlation coefficient or his contribution pattern is monotonically increasing. A free-rider is a subject that always contributes 0. An altruist is a subject who always contributes more than 15 tokens, unconditionally on others' contributions. Overall, about two thirds of the subjects are conditional contributors, with similar shares in both macro-regions (62\% in the North and $70 \%$ in the South). About $7 \%$ of the subjects matched exactly other's contributions. The percentage of free-riders among the Northerners $(17 \%)$ is 
almost twice as large as the percentage among the Southerners (9\%). Altruists account only for a very small fraction of the population ( $2 \%$ in both macro-areas).$^{9}$ The distribution of types is not significantly different across macro-regions (Fischer exact test: p-value $=0.466, N_{N}=52$ and $\left.N_{S}=82\right) 10$ Quite interestingly, also free-riders can contribute to sustain cooperation as they foresee potential gains in maintaining optimistic expectations among conditional cooperators (Fischbacher and Gächter, 2010). This element could be especially pronounced in field situations where social dilemmas are played sequentially. While free-riders would not contribute when they are last movers, they may fully contribute as first mover in an attempt to entice conditional cooperators to contribute. For instance, some free riders could decide to start sweeping the sidewalk to send a signal to conditional cooperators and hence induce them to follow through.

To sum up, the evidence from Experiment 1 shows that the average subject is conditionally cooperative and the strength of this preference is similar among Northerners and Southerners. In a society of conditional cooperators the actual cooperation level in a public good game depends from the strength of cooperative preferences as well as from people's beliefs about others' contribution behaviour. In line with previous evidence, we report that the average subject exhibits imperfect conditional cooperation, which means that an extra unit of contribution by all others would induce the average subject to increase her contribution by less than one unit (Fischbacher et al. 2001$)$. Actual contributions, though, also directly depend on people's beliefs about others' contributions (Fischbacher and Gächter, 2010), and optimistic beliefs can compensate for the imperfect responsiveness from conditionally cooperative preferences. In general, the observed level of cooperation in a society can vary considerably depending on the combined effect of conditionally cooperative preferences and expectations about others' behaviour. The Italian regional gap in cooperation could well originate from different levels of expectations about others' contribution. We explore this mechanism in Experiment 2. In addition, Experiment 2 also studies tolerance for social risk, which could - independently from or jointly with expectations - shape the ability of a society to achieve cooperative outcomes.

\footnotetext{
${ }^{9} 19 \%$ of the participants are not classified according to any of the three types.

${ }^{10}$ In the unconditional decision, subjects contributed on average about half of their endowment (10.49). Contributions were slightly higher among Southerners than Northerners (10.74 vs. 10.08), but the difference was not statistically significant (two-sided Wilcoxon rank-sum test, p-value $=0.579, N_{N}=52$ and $N_{S}=82$ ). OLS regressions provide similar results. Contrary to Bigoni et al. (2016), here participants were interacting with others from all parts of Italy. The geographical composition of the group could indeed affect beliefs about others' contributions and therefore unconditional cooperation.
} 


\section{Experiment 2 on Beliefs and Betrayal Aversion}

\subsection{Design}

In Experiment 2 we elicited betrayal aversion (Part 1) and then beliefs about the ability to cooperate in the North and South of Italy (Part 2). For the sake of exposition, we reverse the order in which we present the tasks.

Beliefs. We asked subjects to estimate the cooperation levels realised in a previous experiment run in the North and South of Italy. The task was a Public Good Game run in separate sessions in the city of Cuneo and Crotone with a representative sample of the Italian population (Figure 1). Before eliciting beliefs, we read the instructions of the original experiment (Bigoni et al. 2016) where it was publicly announced that all participants were born and resident in the province where the experiment was conducted ${ }^{11}$ In the original experiment, subjects interacted for 8 rounds in groups of $N=4$ strangers (random matching) ${ }^{12}$

Each participant had to provide two estimates of the average contribution across 8 rounds, one for Cuneo, the other for Crotone ${ }^{13}$ An estimate had to be an integer number between 0 and 20 tokens. We randomly selected two subjects from the original experiment, one from Crotone, the other from Cuneo. These two random draws were repeated for every session of Experiment 2 to limit information leakage across sessions. Everyone was paid according to one of the two estimates, selected at random, which was then compared to the actual contribution of a single subject taken from the original experiment. Belief elicitation was incentivised by means of a quadratic scoring rule (see the Online Appendix). A subjects could earn up to 26 tokens for an accurate estimate $(+/-1$ token). Deviations larger than 5 tokens yielded zero tokens.

Betrayal aversion. This part comprised two between-subjects treatments - Trust and Risky Dictator - based on the experimental set-up proposed by Bohnet et al. (2008). ${ }^{14}$ Subjects inter-

\footnotetext{
${ }^{11}$ We read the Part 2 instructions from the PGG session of Bigoni et al. (2016), and asked subjects to answer the same control questions.

${ }^{12}$ Payoffs were as in Expression (1) with $w=20, \alpha=0.5$, and $g_{i}=0,6,14$, or 20 .

${ }^{13}$ The list of cities was not disclosed in advance, to avoid any demand effect. The order of the cities was randomised within each session. For each estimate, subjects could see on their screen a map of Italy showing the city location.

${ }^{14}$ We departed from Bohnet et al. $(2008)$ as we used a different payoff structure, rewrote the instructions, and did not run the treatment where subjects played a lottery against nature (i.e. the Decision Problem).
} 
acted in pairs with a first mover (blue) and a second mover (red). Pair matching and roles were randomly determined ${ }^{15}$ Betrayal aversion is measured as the difference in the average choice of the first movers between the Trust and the Risky Dictator treatment.

In the Trust treatment - meant to capture preferences toward social risk - blue faces alternatives A and B (Figure 3). Under alternative A both subjects earn 10 tokens and red takes no decision. Under alternative B, earnings in the pair depend on the choice of red, who can choose between options 1 or 2 . Option 1 delivers 15 tokens to both subjects while with option 2 blue earns 8 tokens and red earns 22 .

The implementation of the game is such that blue (first mover) does not directly choose between the alternatives $\mathrm{A}$ and $\mathrm{B}$, but states under which circumstances he prefers $\mathrm{A}$ over $\mathrm{B}$. More precisely, he states a number between 0 and 100 that indicates the minimum percentage of red (second movers) choosing option 1 that he requires in order to prefer the "risky" alternative B over the "safe" alternative A. This threshold number is called the minimum acceptable probability (MAP, henceforth). Red always makes a choice, without knowing blue's choice in advance. To determine the outcome of the game for a specific pair of subjects, and their payoffs, at the end of each session one needs to compare the MAP chosen by the blue player in the pair with the realised percentage of second movers choosing option 1 in the whole session ( $p$, henceforth). Alternative A was implemented in the pair if the session's $p$ was smaller than the MAP, and alternative B otherwise 16

The Risky Dictator treatment is meant to capture preferences toward the risk of nature. It is alike the Trust treatment, with one difference: reds (second movers) are passive players because their actions are determined by a random draw. The probability of option 1 or 2 being selected was unbeknown to the subjects, and it was determined by the share of second movers' choices observed in one previous session of the Trust treatment. Feedback for the Trust and Risky Dictator tasks were given at the end of the session to avoid any possible carry over effect (see Section 1.2. for detailed procedures).

\footnotetext{
${ }^{15}$ Red and blue subjects were in the same room and read the same instructions.

${ }^{16}$ At the end of the experiments, everyone observed the outcome in his pair.
} 


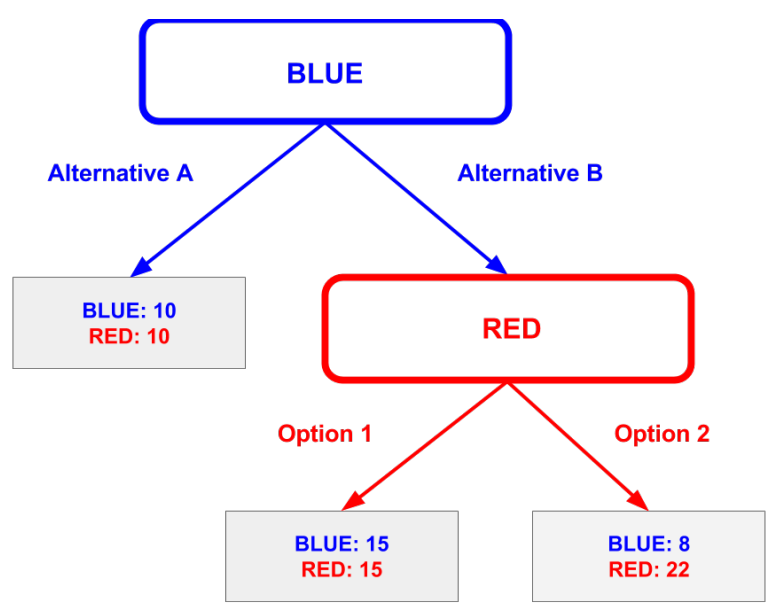

A risk-neutral payoff-maximiser would chose a MAP of about $29 \%$. To see this, one should equalise the certain payoff of 10 from Alternative A to the expected payoff from alternative $\mathrm{B}, 15 p+8(1-p)$, where $p$ denotes the probability that option 1 is selected. The MAP is the probability $p$ that solves this equation. A person with no aversion to betrayal would state the same MAP in the Trust and Risky Dictator treatments. A person that is averse to betrayal would state a higher MAP in the Trust than in the Risky Dictator treatment.

Procedures. Experiment 2 involved 290 subjects (141 from the North and 149 from the South), divided in 16 sessions; session participants ranged from 10 to 31. Earnings were expressed in tokens. The conversion rate was 2 tokens per Euro and the overall average per-capita earnings were 14 Euros, including a 4 Euros show-up fee (see Section 1.2. for other details).

\subsection{Results for Experiment 2}

Result 2 Participants expect higher cooperation in the North than in the South.

Support for Result 2 comes from Figure 4 and Table 2 . There is a widespread belief that people in Cuneo (North) contribute in a Public Good Game more than people in Crotone (South) and this difference is statistically significant (two-sided Wilcoxon signed-rank test: $\mathrm{p}<0.001$, $N=290$ ). More precisely, the average estimate is 10.01 tokens for Cuneo, and 8.90 tokens for Crotone. This belief is shared among participants from both the North and the South (two-sided Wilcoxon signed-rank test: $\mathrm{p}$-value $=0.003, N=141 ; \mathrm{p}<0.001, N=149$, respectively). 
This result is confirmed by regressions in Table 2, Subjects on average believe that contributions are 1.1 tokens higher in Cuneo than in Crotone (Model 1). In Model 2, we include a dummy for people who were born in the North, and interact the variable Cuneo with North and South dummies. The difference between the two estimated coefficients of the interacted variables is not statistically significant $(\mathrm{p}$-value $=0.836)$. This result holds even if we restrict the sample to subjects rooted in their macro-area (Model 3, p-value=0.769).

Figure 4: Beliefs about Cooperation

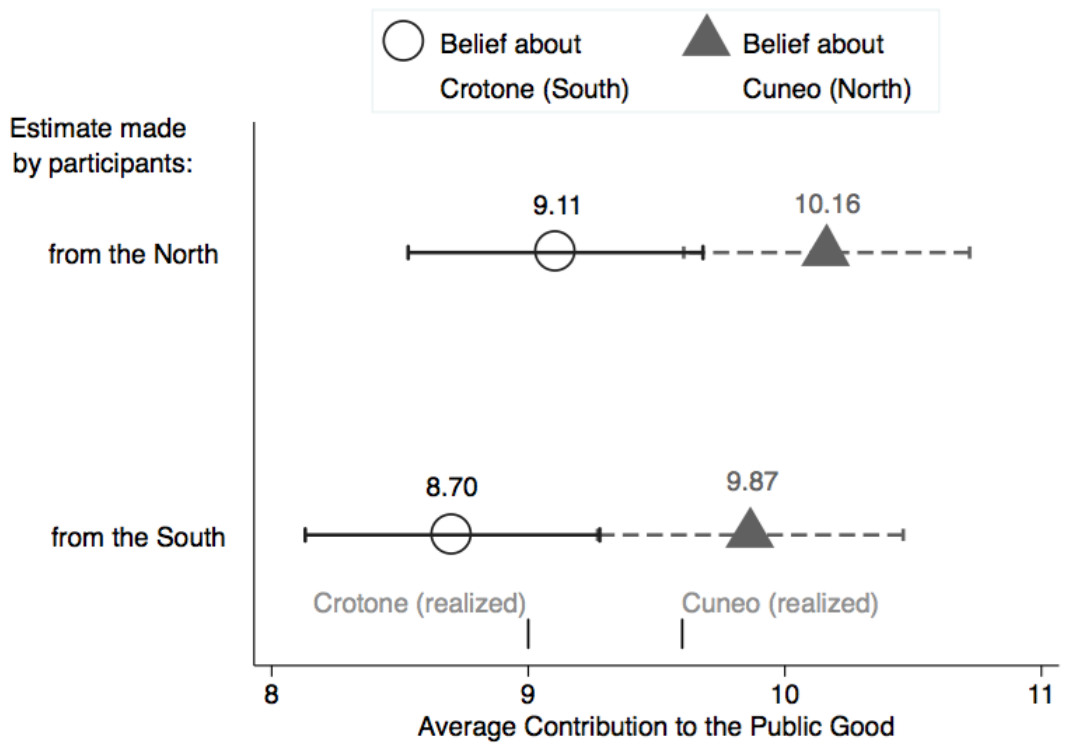

Notes: the vertical dashes report the average contribution levels observed in Bigoni et al. (2016). The whiskers denote $90 \%$ confidence intervals.

Result 3 Participants from the South display a significant aversion to betrayal.

Support for Result 3 comes from Table 3 . Following Bohnet et al. (2008) we say that there is betrayal aversion if the minimum acceptable probability stated in the Trust treatment is higher than in the Risky Dictator treatment. We measure betrayal aversion at the aggregate level, and not at the individual level, because of the between-subject design.

Subjects from the South of Italy display a substantial degree of betrayal aversion (62.1 $49.0=13.1$ percentage points, $N=72$ ) which is statistically significant (two-sided Wilcoxon rank-sum test, p-value $=0.027, N_{T}=38$ and $N_{R D}=36$ ). The degree of betrayal aversion 
Table 2: Regression on Beliefs about Cooperation

\begin{tabular}{lccc}
\hline \hline Dep.var.: Belief about avg. contrib. & \multicolumn{2}{c}{ Entire sample } & Rooted \\
in a PGG in Cuneo or Crotone & Model 1 & Model 2 & Model 3 \\
\hline Cuneo & $1.110^{* * *}$ & & \\
& $(0.251)$ & & \\
North & & 0.090 & 0.007 \\
& & $(0.514)$ & $(0.559)$ \\
Cuneo x North & $1.057^{* * *}$ & $1.106^{* * *}$ \\
& & $(0.361)$ & $(0.399)$ \\
Cuneo x South & & $1.161^{* * *}$ & $1.262^{* * *}$ \\
& & $(0.351)$ & $(0.352)$ \\
& & & \\
Controls & Yes & Yes & Yes \\
& & & \\
Constant & $8.193^{* * *}$ & $8.161^{* * *}$ & $7.937^{* * *}$ \\
& $(0.578)$ & $(0.598)$ & $(0.622)$ \\
\hline N.obs., N.subjects & 580,290 & 580,290 & 516,258 \\
$\mathrm{R}^{2}$ & 0.059 & 0.059 & 0.076 \\
\hline
\end{tabular}

Notes: OLS regression with individual-level random effects. Every subject makes two estimates. See notes to Table 1 for a description of Controls. Default location is Crotone (South). $* * *$ statistical significance at the $1 \%$ level.

Table 3: Regression on Betrayal Aversion

\begin{tabular}{lccc}
\hline \hline Dep. var.: MAP in Trust & \multicolumn{2}{c}{ Entire sample } & Rooted \\
and Risky Dictator treatments & Model 1 & Model 2 & Model 3 \\
\hline Trust treatment & $10.374^{* *}$ & & \\
& $(4.091)$ & & \\
North & & 4.862 & 4.914 \\
& & $(6.156)$ & $(6.627)$ \\
Trust treatment x North & & 6.905 & 10.581 \\
& & $(6.029)$ & $(7.033)$ \\
Trust treatment x South & & $(5.567)$ & $(5.586)$ \\
& & & \\
Controls & Yes & Yes & Yes \\
& & & \\
Constant & $39.001^{* * *}$ & $37.859^{* * *}$ & $37.691^{* * *}$ \\
& $(6.229)$ & $(6.407)$ & $(6.667)$ \\
\hline N.obs. & 146 & 146 & 128 \\
$\mathrm{R}^{2}$ & 0.081 & 0.086 & 0.110 \\
\hline
\end{tabular}

Notes: OLS regression. One observation per subject. See notes to Table 1 for a description of Controls. Default decision refers to the Risky Dictator treatment. $* * *$ and $* *$ statistical significance at the $1 \%$ and $5 \%$ level, respectively.

among subjects from the North is much smaller $(60.6-57.8=2.8$ percentage points, $N=74)$ and is not statistically significant (two-sided Wilcoxon rank-sum test, p-value $=0.552, N_{T}=40$ 
and $N_{R D}=32$ ).

These results are confirmed by the OLS regressions presented in Table 3 . Model 1 shows that overall participants display betrayal aversion. Models 2 and 3 reveal that betrayal aversion is significant only for subjects from the South (Trust treatment $\times$ South). According to an F-test, however, the degree of betrayal aversion does not significantly differ among Southerners and Northerners $(\mathrm{p}$-value $=0.436$ for Model 2, $\mathrm{p}$-value $=0.773$ for Model 3 )

\section{Discussion and Conclusions}

Our study reveals that the gap in ability to cooperate between the North and South of Italy does not lie in differences in pro-social preferences. Surprisingly in view of popular narratives, the level of conditional cooperation we found among people from the South is similar to that of people from the North. In a Public Good Game experiment people from both macro-regions respond to an increase in the contribution of others in ways that are statistically indistinguishable. In theory, self-selection could be an issue, but the evidence we have on college choice of Italian students allays this concern (Casari et al. 2018).

The cause of the difference in cooperative ability lies elsewhere. First, Northerners and Southerners differ in their betrayal aversion, which is present among the latter, but negligible among the former. The pattern of statistical significance, based on the behaviour in a Trust Game, however, is inconclusive: betrayal aversion differs significantly from zero among Southerners but not among Northerners, yet the two values do not significantly differ from each other. The low number of subjects (ca. 70) may have something to do with this. It is nonetheless tempting to speculate on this result as it seems a promising avenue of further study. A more intense aversion to betrayal could be due to engrained conventional values that hold people who are cheated in lower esteem than people who cheat - "fool me once shame on me." Or it could be a response to higher expected cost of being cheated, the fear of having to bear the cost of redress and reputation re-building personally rather than rely on public or social justice.

In conclusion, the regional difference in behaviour is not rooted in individual pro-social 
preferences, as Banfield suggested. What matters are the differences in betrayal aversion and, above all, in the beliefs about others' cooperative behavior: our more robust result puts the responsibility for cooperation disparities squarely on the more pessimistic expectations that Southerners have about other Southerners' contribution, displayed in the Public Good Game, than Northerners have about other Northerners'.

Department of Economics, University of Bologna \& IZA

Max Planck Institute for Research on Collective Goods, Bonn $\&$ C-SEB

Department of Economics, University of Bologna 83 IZA

European University Institute $\&$ Nuffield College, University of Oxford

Additional Supporting Information may be found in the online version of this article: Appendix A: Experimental Instructions 


\section{References}

Banfield, E.C. and Fasano, L. (1958). The Moral Basis of a Backward Society, The Free Press.

Barr, A. and Serra, D. (2010). 'Corruption and culture: An experimental analysis', Journal of Public Economics, vol. 94, pp. 862-869.

Battiston, P. and Gamba, S. (2016). 'When the two ends meet: An experiment on cooperation across the Italian North-South divide', Laboratory of Economics and Management (LEM), Sant'Anna School of Advanced Studies, Pisa, Italy.

Bigoni, M., Bortolotti, S., Casari, M., Gambetta, D. and Pancotto, F. (2016). 'Amoral familism, social capital, or trust? The behavioural foundations of the Italian North-South Divide', The Economic Journal, vol. 126(594), pp. 1318-1341.

Bisin, A. and Verdier, T. (2000). 'Beyond the Melting Pot: Cultural Transmission, Marriage, and the Evolution of Ethnic and Religious Traits', Quarterly Journal of Economics, vol. 115(3), pp. $955-988$.

Bohnet, I., Greig, F., Herrmann, B. and Zeckhauser, R. (2008). 'Betrayal Aversion: Evidence from Brazil, China, Oman, Switzerland, Turkey, and the United States', American Economic Review, vol. 98(1), pp. 294-310.

Bohnet, I. and Zeckhauser, R. (2004). 'Trust, risk and betrayal', Journal of Economic Behavior 86 Organization, vol. 55(4), pp. 467-484.

Bornhorst, F., Ichino, A., Kirchkamp, O., Schlag, K.H. and Winter, E. (2010). 'Similarities and differences when building trust: The role of cultures', Experimental Economics, vol. 13(3), pp. 260-283.

Brosig-Koch, J., Helbach, C., Ockenfels, A. and Weimann, J. (2011). 'Still different after all these years: Solidarity behavior in East and West Germany', Journal of Public Economics, vol. 95(11-12), pp. 1373-1376.

Buonanno, P., Montolio, D. and Vanin, P. (2009). 'Does social capital reduce crime?', Journal of Law and Economics, vol. 52(1), pp. pp. 145-170.

Cartocci, R. (2007). Mappe del tesoro: atlante del capitale sociale in Italia, Il mulino. 
Casari, M., Ichino, A., Michaeli, M., De Paola, M., Scoppa, V. and Marandola, G. (2018). 'Civicness Drain', European University Institute Working Paper.

Cubitt, R.P., Gächter, S. and Quercia, S. (2017). 'Conditional cooperation and betrayal aversion', Journal of Economic Behavior \& Organization, vol. 141, pp. 110 - 121.

Dohmen, T., Falk, A., Huffman, D. and Sunde, U. (2012). 'The Intergenerational Transmission of Risk and Trust Attitudes', Review of Economic Studies, vol. 79(2), pp. 645-677.

Ezcurra, R. and Rodríguez-Pose, A. (2013). 'Does economic globalization affect regional inequality? A cross-country analysis', World Development, vol. 52, pp. 92-103.

Fischbacher, U. (2007). 'z-Tree: Zurich toolbox for ready-made economic experiments', Experimental Economics, vol. 10(2), pp. 171-178.

Fischbacher, U. and Gächter, S. (2010). 'Social preferences, beliefs, and the dynamics of free riding in public goods experiments', American Economic Review, vol. 100(1), pp. 541-56.

Fischbacher, U., Gächter, S. and Fehr, E. (2001). 'Are people conditionally cooperative? Evidence from a public goods experiment', Economics Letters, vol. 71(3), pp. 397-404.

Frederick, S. (2005). 'Cognitive reflection and decision making', The Journal of Economic Perspectives, vol. 19(4), pp. 25-42.

Greiner, B. (2015). 'Subject pool recruitment procedures: Organizing experiments with orsee', Journal of the Economic Science Association, vol. 1(1), pp. 114-125.

Guiso, L., Sapienza, P. and Zingales, L. (2004). 'The role of social capital in financial development', American Economic Review, vol. 94(3), pp. 526-556.

Kocher, M.G., Cherry, T., Kroll, S., Netzer, R.J. and Sutter, M. (2008). 'Conditional cooperation on three continents', Economics Letters, vol. 101(3), pp. 175-178.

Nannicini, T., Stella, A., Tabellini, G. and Troiano, U. (2013). 'Social capital and political accountability', American Economic Journal: Economic Policy, vol. 5(2), pp. 222-50.

Putnam, R., Leonardi, R. and Nanetti, R. (1993). Making Democracy Work: Civic Traditions in Modern Italy, Princeton University Press. 
Rustagi, D., Engel, S. and Kosfeld, M. (2010). 'Conditional cooperation and costly monitoring explain success in forest commons management', Science, vol. 330(6006), pp. 961-965.

Rustagi, D. and Veronesi, M. (2016). 'Social identity, attitudes towards cooperation, and social preferences: Evidence from Switzerland', University of Verona, Department of Economics. 